\title{
The genetic contribution to sex determination and number of sex chromosomes vary among populations of common frogs (Rana temporaria)
}

\author{
N Rodrigues ${ }^{1}$, Y Vuille ${ }^{1}$, A Brelsford ${ }^{1,3}, \mathrm{~J} \mathrm{Merilä}^{2}$ and N Perrin ${ }^{1}$ \\ The patterns of sex determination and sex differentiation have been shown to differ among geographic populations of common \\ frogs. Notably, the association between phenotypic sex and linkage group $2\left(L_{2}\right)$ has been found to be perfect in a northern \\ Swedish population, but weak and variable among families in a southern one. By analyzing these populations with markers from \\ other linkage groups, we bring two new insights: (1) the variance in phenotypic sex not accounted for by $L_{2}$ in the southern \\ population could not be assigned to genetic factors on other linkage groups, suggesting an epigenetic component to sex \\ determination; (2) a second linkage group $\left(L_{7}\right)$ was found to co-segregate with sex and $L G_{2}$ in the northern population. Given \\ the very short timeframe since post-glacial colonization (in the order of 1000 generations) and its seemingly localized \\ distribution, this neo-sex chromosome system might be the youngest one described so far. It does not result from a fusion, but \\ more likely from a reciprocal translocation between the original $Y$ chromosome $\left(L_{2}\right)$ and an autosome $\left(L G_{7}\right)$, causing their co- \\ segregation during male meiosis. By generating a strict linkage between several important genes from the sex-determination \\ cascade (Dmrt1, Amh and Amhr2), this neo-sex chromosome possibly contributes to the 'differentiated sex race' syndrome \\ (strictly genetic sex determination and early gonadal development) that characterizes this northern population.
}

Heredity (2016) 117, 25-32; doi:10.1038/hdy.2016.22; published online 13 April 2016

\section{INTRODUCTION}

Although sex determination is considered as mostly genetic in amphibians, $96 \%$ of species investigated so far present homomorphic sex chromosomes (Eggert, 2004). Homomorphy may result from occasional X-Y recombination and/or frequent sex-chromosome turnovers (see, for example, Stöck et al., 2011; Dufresnes et al., 2015), two mechanisms possibly driven by incomplete genetic control over sex determination (Perrin, 2009; Grossen et al., 2011). Sexdetermination systems seem particularly labile in Ranidae, where sex chromosomes may differ between closely related species or even conspecific populations (Nishioka and Sumida, 1994; Miura, 2007).

In common frogs (Rana temporaria), sex associates with linkage group $2\left(\mathrm{LG}_{2}\right)$, as first discovered by sex differences in allele frequencies at microsatellite markers (Matsuba et al., 2008; Alho et al., 2010; Cano et al., 2011; Rodrigues et al., 2013). However, the strength of association varies within and among populations (Matsuba et al., 2008; Rodrigues et al., 2013), seemingly with a cline in sexchromosome differentiation along a latitudinal transect in Sweden (Rodrigues et al., 2014). In the northern-boreal population of Ammarnäs, all $\mathrm{LG}_{2}$ markers display marked differences between sexes, with male-specific alleles testifying to a male-heterogametic system (XY males, XX females) and absence of X-Y recombination in its recent history. In the southern population of Tvedöra, in contrast, the same $\mathrm{LG}_{2}$ markers do not show any sex differentiation: males and females present the same alleles at similar frequencies. Intermediate populations display a mixed situation, some males being characterized by a differentiated $\mathrm{Y}$ haplotype, whereas others are genetically identical to females (Rodrigues et al., 2014).

Three alternative hypotheses were proposed to account for these patterns (Rodrigues et al., 2014): (1) sex is determined by the same chromosome pair throughout Sweden (that is, $\mathrm{LG}_{2}$ ), but populations differ in $\mathrm{X}-\mathrm{Y}$ recombination rates; (2) sex associates with a different linkage group in the south; and (3) sex determination is not genetic in the south. To distinguish among these hypotheses, Rodrigues et al. (2015) analyzed with the same $\mathrm{LG}_{2}$ markers six families from each of the two most contrasted populations (Ammarnäs and Tvedöra) for patterns of recombination and association with offspring phenotypic sex. Families from these two populations displayed very similar rates of recombination (very high in females and close to zero in males), hence discarding hypothesis (1). However, patterns of gonadal development among offspring were strikingly dissimilar: Ammarnäs could be assigned to the 'differentiated sex race' (Witschi, 1929, 1930), where most juveniles present already at metamorphosis (Gosner stage 43; Gosner, 1960) either ovaries or testes in equal proportions, whereas Tvedöra belonged to the 'semi-differentiated sex race' where most juveniles present ovaries at this stage; only later in development (around Gosner stage 46) do some of them replace ovaries by testes. Sibship analyses also revealed striking differences in the association

\footnotetext{
${ }^{1}$ Department of Ecology and Evolution, University of Lausanne, Lausanne, Switzerland and ${ }^{2}$ Ecological Genetics Research Unit, Department of Biosciences, University of Helsinki, Helsinki, Finland

Correspondence: N Rodrigues, Department of Ecology and Evolution, University of Lausanne, CH-1015 Lausanne, Switzerland.

E-mail: nicolas.rodrigues@unil.ch

${ }^{3}$ Current address: Department of Biology, University of California at Riverside, Riverside, CA, USA.

Received 18 November 2015; revised 24 February 2016; accepted 26 February 2016; published online 13 April 2016
} 
between offspring phenotypic sex and paternally inherited $\mathrm{LG}_{2}$ haplotypes, which was close to perfect in Ammarnäs, but much weaker in Tvedöra (though highly significant overall) and very variable among families (range 0.0-1.0). This clearly attests to a weak and variable but significant contribution of $\mathrm{LG}_{2}$ to sex determination in this population, despite the absence of differentiated $\mathrm{X}$ and $\mathrm{Y}$ haplotypes.

The question remained of whether the unexplained part of variance in phenotypic sex in Tvedöra stemmed from the implication of another linkage group or from a nongenetic contribution to sex determination. To address this question, we analyze here these families for microsatellite markers on different linkage groups. Our predictions are straightforward: if the first alternative is correct, then we expect a linkage group other than $\mathrm{LG}_{2}$ to associate with sex in families from Tvedöra (but not in those from Ammarnäs), possibly with sex differences in allelic frequencies at the population level. If the second alternative is correct, we expect no additional association in any population, besides that already documented for $\mathrm{LG}_{2}$.

\section{MATERIALS AND METHODS}

\section{Frog sampling and pedigree building}

The present study uses samples collected during spring 2013 from two Swedish populations (Table 1), already analyzed for $13 \mathrm{LG}_{2}$ markers by Rodrigues et al. (2015). Eleven pairs were captured in amplexus from 16 to 20 April in the southern locality of Tvedöra $\left(55^{\circ} 42^{\prime} 0.85^{\prime \prime} \mathrm{N}, 13^{\circ} 25^{\prime} 50.91^{\prime \prime} \mathrm{E}\right)$, and 20 pairs from 17 to 20 May in the northern-boreal population of Ammarnäs $\left(65^{\circ} 58^{\prime} 12.60^{\prime \prime} \mathrm{N}\right.$, $\left.16^{\circ} 12^{\prime} 43.80^{\prime \prime} \mathrm{E}\right)$. Mating pairs were allowed to spawn in 111 plastic boxes, then sampled for buccal cells (sterile cotton swabs; Broquet et al., 2007) before release at the place of capture. Newly hatched tadpoles from 12 families (6 from Ammarnäs and 6 from Tvedöra) were brought to the University of Lausanne, and each family kept separately in 5001 tanks in outdoor facilities. Within 1 week of metamorphosis (stage 43; Gosner, 1960), 40 individuals per family (referred to as metamorphs) were anesthetized and killed in $0.2 \%$ ethyl-3aminobenzoate methanesulfonate (MS222) salt solution and then preserved in $70 \%$ ethanol. The remaining individuals (referred to as froglets) continued development until reaching $20 \mathrm{~mm}$ snout-vent length (stage 46; Gosner, 1960), before being anesthetized and killed following the same protocol. All metamorphs and froglets were dissected under a binocular microscope to identify phenotypic sex based on gonad morphology. Ovaries in common frogs develop from the whole gonadal primordia into a large whitish/yellowish structure with distinct lobes, and a characteristic granular aspect conferred by the many oocytes embedded in the cortex (Ogielska and Kotusz, 2004). In contrast, testes develop from the anterior part of the gonadal primordia only (the posterior part degenerates) into a small oblong structure, with a smooth cortex covered by melanic spots (Haczkiewicz and Ogielska, 2013). In case of doubt, gonads were considered as undifferentiated and sex was not assigned.

This study also includes 265 adult frogs sampled during the springs of 1998 and 1999 from six Swedish populations (Esrange, Ammarnäs, HamptjärnGrytan, Häggedal, Lindrågen and Tvedöra; Table 1), already analyzed for the same $13 \mathrm{LG}_{2}$ markers by Rodrigues et al. (2014). Tissue samples (muscle and liver) were collected from all individuals and preserved in ethanol $90 \%$ at $-80^{\circ} \mathrm{C}$. DNA extractions were performed using a silica-based method as described in Ivanova et al. (2006). Phenotypic sex of wild-caught frogs was identified on the basis of secondary sexual traits (that is, white throat and presence of nuptial pads in males and red coloration and presence of eggs in females) and later confirmed by dissection for the purpose of other studies (Hettyey et al., 2005; Hjernquist et al., 2012).

\section{Lab work}

Swabs and tissue samples were digested overnight in a $10 \%$ proteinase $\mathrm{K}$ (Qiagen, Hilden, Germany) solution at $56^{\circ} \mathrm{C}$; DNA was extracted using a Biosprint 96 workstation (Qiagen), resulting in $200 \mu$ l Buffer AE (Qiagen) DNA

Table 1 Summary of adult and family samples used in the present study

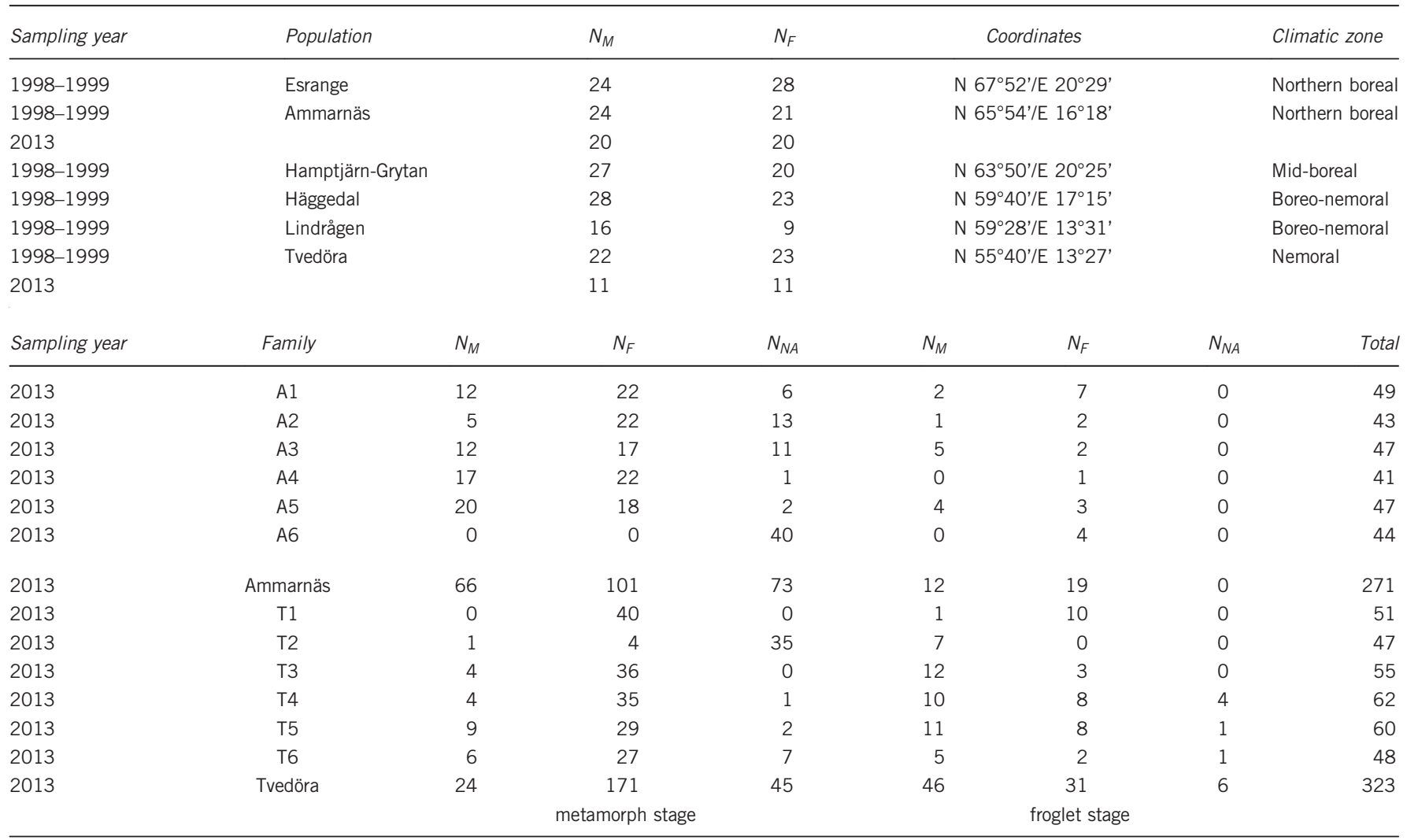

Abbreviations: $N_{\mathrm{F}}$, number of females; $N_{\mathrm{M}}$, number of males; $N_{\mathrm{NA}}$, number of offspring with undifferentiated gonads. 
elutions. In line with our hypotheses (see Introduction), we first genotyped all 83 froglets from the six Tvedöra families (adding Ammarnäs family A5 as a control) for 49 additional markers from all linkage groups other than $\mathrm{LG}_{2}$ described by Cano et al. (2011) and Rodrigues et al. (2013), combined into seven Multiplex mixes (Supplementary Table S1). Following evidence for sex linkage of $\mathrm{LG}_{7}$ in Ammarnäs (see Results), we then further genotyped the whole 2013 sampling (62 adults, 480 metamorphs and 114 froglets) as well as the 1998 and 1999 samples (265 adults from six populations) for $13 \mathrm{LG}_{7}$ markers, combined in two Multiplex mixes (Supplementary Table S1). PCR reactions were performed with a total volume of $10 \mu \mathrm{l}$, including 1 or $3 \mu \mathrm{l}$ of extracted DNA, $3 \mu \mathrm{l}$ of Qiagen Multiplex Master Mix 2x, and 0.1 to $0.6 \mu$ l of labeled forward primer and unlabeled reverse primer (Supplementary Table S1). PCRs were run on Perkin Elmer (Waltham, MA, USA) 2700 machines using the following thermal profile: $15 \mathrm{~min}$ of Taq polymerase activation at $95^{\circ} \mathrm{C}$, followed by 35 cycles including denaturation at $94^{\circ} \mathrm{C}$ for $30 \mathrm{~s}$, annealing at $57^{\circ} \mathrm{C}$ for $1 \mathrm{~min} 30 \mathrm{~s}$ and elongation at $72^{\circ} \mathrm{C}$ for $1 \mathrm{~min}$, ending the PCR with a final elongation of $30 \mathrm{~min}$ at $60^{\circ} \mathrm{C}$. PCR products for genotyping were run on an automated ABI Prism 3100 sequencer (Applied Biosystems, Foster City, CA, USA) and alleles were scored on GENEMAPPER v4.0 (Applied Biosystems).

\section{Linkage groups and recombination maps}

Recombination maps were built with CRIMAP v2.4 (Green et al., 1990) Sex-specific recombination rates between all possible pairs of the whole set of 49 markers were calculated separately for the six Tvedöra families and for the Ammarnäs family A5, running the TWOPOINT option; all pairwise associations with a LOD (logarithm (base 10) of odds) score exceeding 3.0 were considered significant. Loci were then ordered within linkage groups by running the ALL and FLIPS options; the BUILD option was used to calculate recombination distances between loci (Green et al., 1990) and sex-specific recombination maps were built with MAPCHART v2.2 (Voorrips, 2002). Following the second round of genotyping, population- and sex-specific maps were performed for $\mathrm{LG}_{2}$ and $\mathrm{LG}_{7}$ by including all 594 offspring from the 12 families. Correspondences between $R$. temporaria linkage groups and Xenopus tropicalis $(X t)$ chromosomes were established based on one Swiss $R$. temporaria family (C1) that was analyzed for both microsatellites (Rodrigues et al., 2013) and genotyping-by-sequencing reads (Brelsford et al., 2016). See Brelsford et al. (2016) for details of the procedure of orthology search.

\section{Statistical analyses}

The correlation between paternal allele inheritance and phenotypic sex was quantified by phi-square (an index of association ranging from 0 to 1 , given by $\phi^{2}=\chi^{2} / n$ where $n=$ sample size), and tested with Fisher's exact test for all 49 markers and 7 families from Tvedöra and Ammarnäs analyzed in the first round of genotyping.

Following the second round of genotyping, sex differentiation at $\mathrm{LG}_{7}$ was investigated in all adults from these two populations (2013 sampling) via within- $\left(F_{\mathrm{IS}}\right)$ and between-sexes $\left(F_{\mathrm{ST}}\right)$ fixation indices (FSTAT v. 2.9.4; Goudet, 1995). LG 7 sex haplotypes were then phased in Ammarnäs as described by Rodrigues et al. (2015), and analyzed for expected heterozygosity $H_{\mathrm{S}}$ and differentiation $F_{\mathrm{ST}}$ (FSTAT v. 2.9.4; Goudet, 1995). Genetic diversity $\theta$ was calculated from $H_{\mathrm{S}}$ as $\theta=\left(\left(1-H_{\mathrm{S}}\right)^{-2}-1\right) / 2$, assuming a stepwise mutation model (Kimura and Ohta, 1975). At neutral equilibrium, the $\theta$ value for locus $i$ is expected to reflect the effective population size $N_{e}$, mutation rate $m_{i}$ and number of copies per breeding pair $c_{i}: \theta_{i}=c_{i} N_{e} m_{i}$. Thus, values for X-linked and Y-linked markers should represent three-fourths and one-fourth of autosomal values, respectively, assuming similar effective population sizes and mutation rates, and absence of $\mathrm{X}-\mathrm{Y}$ recombination.

Finally, we used the first factors of principal component analyses performed on allele frequencies (PCAGEN v.2.0; Goudet, 1999) to visualize X-Y differentiation in Ammarnäs (2013 samples), as well as sex differentiation in the whole set of populations (1998-1999 samples).

\section{RESULTS}

\section{Recombination maps and sex linkage}

The 49 loci involved in the first round of genotyping ( 6 families from Tvedöra and1 from Ammarnäs) gathered into 9 linkage groups, leaving 4 unlinked markers. Families did not differ in terms of linkage groups, loci orders or recombination rates, and were therefore combined in a single analysis, the results of which are plotted in Figure 1. These linkage groups are the same as described from Swiss populations by Rodrigues et al. (2013), hence suggesting their conservation across the species range. The only noticeable difference concerned Bfg203 and Bfg238 (Figure 1b), known to belong to the same linkage group (Rodrigues et al., 2013), but not significantly associated in the present data set because of insufficient polymorphism (LOD score $=1.54)$. Correspondences between $R$. temporaria linkage groups and $X t$ chromosomes are provided in Figure 1 with the same nomenclature as in Brelsford et al. (2016). Separate male and female maps were produced because of large sex differences in recombination rates ( $92.4 \mathrm{~cm}$ total map in males vs $1603.2 \mathrm{~cm}$ in females, including $\mathrm{LG}_{2}$ ), in line with the strong heterochiasmy that characterizes amphibians. The strengths of associations between offspring phenotypic sex and paternal haplotypes ( $\phi^{2}$ values) are provided in Supplementary Table S2. Families from Tvedöra did not show further sex linkage besides that already documented for $\mathrm{LG}_{2}$. Surprisingly, however, offspring sex in the Ammarnäs family A5 displayed a strong and highly significant association with the paternal $\mathrm{LG}_{7}$ haplotype.

Based on this latter result, all families were genotyped for $13 \mathrm{LG}_{7}$ markers, and data combined with the $13 \mathrm{LG}_{2}$ markers genotyped by Rodrigues et al. (2015) for further analyses. Recombination maps (Figure 1a) show that $\mathrm{LG}_{2}$ and $\mathrm{LG}_{7}$ gather into a single linkage group in all Ammarnäs families, with no male recombination (male map $=0.0 \mathrm{~cm}$ ). Consequently, paternal $\mathrm{LG}_{2}$ and $\mathrm{LG}_{7}$ haplotypes present identical patterns of inheritance. Association with offspring phenotypic sex was thus identical to that documented for $\mathrm{LG}_{2}$ by Rodrigues et al. (2015), that is, perfect at both metamorph and froglet stages $\left(\phi^{2}=1\right)$ in all families except $A_{1}$ and $A_{5}$, where association scores in metamorphs were 0.88 and 0.90 respectively, because of a sex-reversed $\mathrm{XY}$ female in each (that is, two metamorphs that presented ovaries despite having inherited their father's $\mathrm{Y}$ haplotype). $\mathrm{LG}_{2}$ and $\mathrm{LG}_{7}$ markers are also assembled in the same linkage group on the female map, although separated by a large gap. Moreover, inverting the relative positions of the $L G_{2}$ and $L_{7}$ groups (four possible alternatives) did not affect the fit (all LOD score differences $<1$ ), strongly suggesting independent segregation in females. Hence, their assemblage in the female map appears to result solely from their linkage in males (CRIMAP cannot produce different linkage groups for males and females). In Tvedöra, by contrast, $\mathrm{LG}_{2}$ and $\mathrm{LG}_{7}$ markers segregated independently in both sexes, and $\mathrm{LG}_{7}$ did not show any association with sex.

\section{Population-genetic analyses}

Estimations of fixation indices in adults (Table 2) pointed to strong and significant differentiation between sexes at both $\mathrm{LG}_{2}$ and $\mathrm{LG}_{7}$ in Ammarnäs $\left(F_{\mathrm{ST}}=0.108\right.$ and 0.096 , respectively), as well as strong heterozygosity excess in males ( $F_{I S}=-0.235$ and -0.236 respectively), testifying to a male heterogametic system with well-differentiated sex haplotypes on both linkage groups. $F_{I S}$ values did not differ significantly from 0 in females from Ammarnäs, and neither did any of the fixation indices in Tvedöra.

Thanks to the marked $\mathrm{X}-\mathrm{Y}$ differentiation (combined with information on offspring sex and genotypes), $\mathrm{LG}_{7}$ sex haplotypes could be phased in all males from Ammarnäs in the same way as performed for $\mathrm{LG}_{2}$ by Rodrigues et al. (2015). Principal component analysis plots (Figure 2) show two distinct clusters corresponding to the $\mathrm{X}$ and $\mathrm{Y}$ haplotypes $\left(F_{\mathrm{ST}}=0.415\right.$ for $\mathrm{LG}_{2}, 0.441$ for $\left.\mathrm{LG}_{7}\right)$. Male $\mathrm{X}$ haplotypes perfectly colocalize with XX females, corroborating our haplotype 
phasing. Interestingly, one male $\left(\mathrm{A}_{17 \mathrm{M}}\right)$ had a $\mathrm{Y}$ haplotype intermediate between the $\mathrm{X}$ and $\mathrm{Y}$ clusters for both $L_{2}$ and $L_{7}$. Discarding this individual, expected heterozygosity on $\mathrm{LG}_{7}$ was 2.5 times lower on the $\mathrm{Y}$ than on the $\mathrm{X}\left(H_{\mathrm{S}}=0.20\right.$ and 0.51 , respectively, averaged over 13 loci), leading to genetic diversity indices 5.7 times smaller on the $\mathrm{Y}$ than on the $\mathrm{X}(\theta=0.28$ and 1.59 , respectively). Corresponding values for $\mathrm{LG}_{2}$ were $H_{\mathrm{S}}=0.29$ and 0.69 respectively (averaged over 13 loci), providing diversity indices 9.6 times smaller on the $\mathrm{Y}$ than on the $\mathrm{X}(\theta=0.48$ and 4.61 , respectively). Haplotype phasing was not possible in males from Tvedöra because of the lack of $\mathrm{X}-\mathrm{Y}$ differentiation on $\mathrm{LG}_{2}$ and absence of sex linkage for $\mathrm{LG}_{7}$.

Principal component analysis plots of $\mathrm{LG}_{7}$ for the six populations from the 1998 to 1999 samples (Figure 3) show that, contrasting with $\mathrm{LG}_{2}$, sex differentiation at $\mathrm{LG}_{7}$ only occurs in Ammarnäs (Figure 3a): all other populations display a complete overlap between male and female distributions (Figures $3 \mathrm{~b}-\mathrm{f}$ ).

\section{DISCUSSION}

Our study provides two main new results on the intriguing sexdetermination system of common frogs. First, no linkage group or marker other than $\mathrm{LG}_{2}$ displayed any sex linkage in the southern population of Tvedöra ('semi-differentiated race'). Second, $\mathrm{LG}_{7}$ showed perfect co-segregation with both $\mathrm{LG}_{2}$ and sex in the northern population of Ammarnäs ('differentiated race'). These two results are discussed in turn below.

The 11 linkage groups identified in Figure 1 could be assigned to 11 of the $13 R$. temporaria chromosomes (labeled here as 1, 2, 3, 4A, 4B, $5,6,7 \mathrm{~A}, 7 \mathrm{~B}, 8 \mathrm{~B}$ and 9 , respectively, according to their $X t$ homologs). Given the very low rate of male recombination overall, the three unassigned markers, two of which are linked, are expected to segregate indeed independently, and therefore to lie on the two remaining chromosomes $8 \mathrm{~A}$ and 10 . Hence, we expect our markers to cover the complete set of 13 chromosome pairs. Of these, only $\mathrm{LG}_{2}$ shows some sex linkage in Tvedöra that is furthermore incomplete and variable among families (Rodrigues et al., 2015). Sibship analyses with sexed offspring have a very high power to detect genetic sex-determination systems, thanks to strong within-family linkage (Brelsford et al., 2016). Hence, although we cannot exclude a polygenic system involving many genes with minor effects spread on multiple chromosomes, our present data might also suggest that the part of variance in phenotypic sex not accounted for by $\mathrm{LG}_{2}$ in this population is not of genetic origin. This suggestion is corroborated by recent RADseq evidence for a complete absence of any genetic component to sex determination in a $R$. temporaria family from a Swiss lowland population (Brelsford et al., 2016). Altogether, these results provide additional support for the suggestion that 'sex races' in $R$. temporaria differ in the epigenetic a

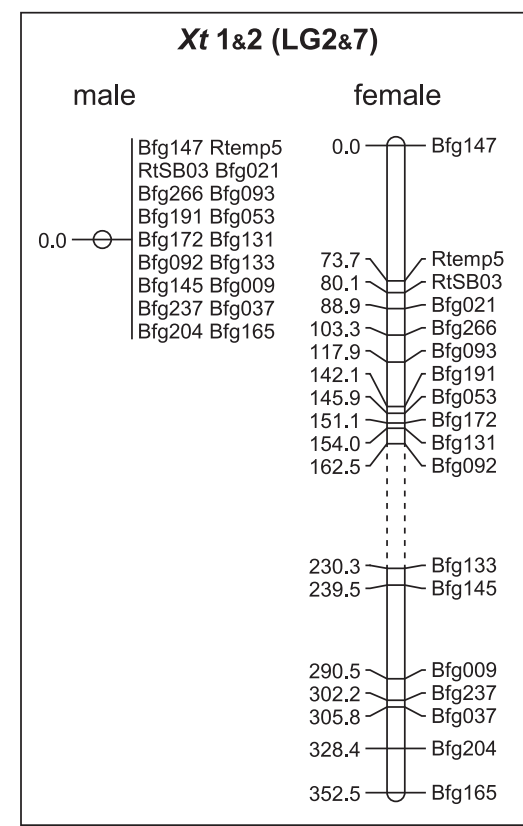

Tvedöra

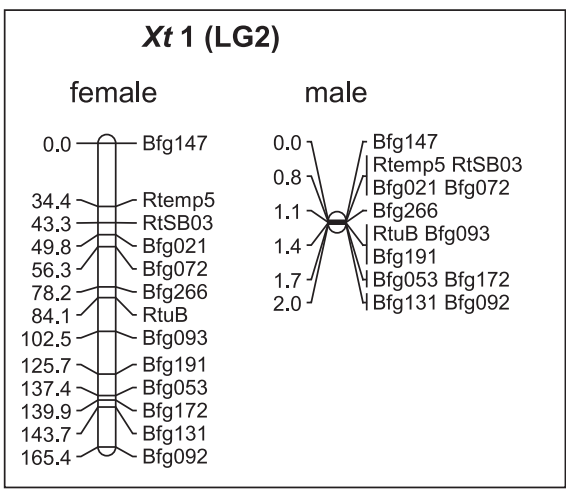

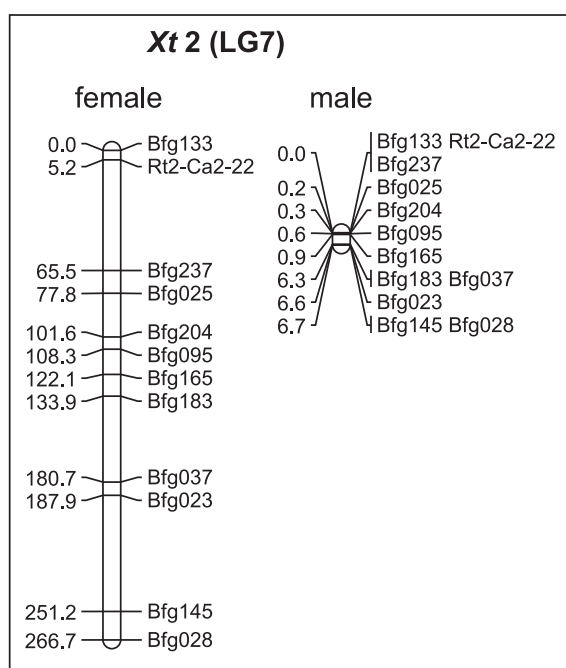

Figure 1 Sex-specific recombination maps of 62 loci for Ammarnäs and Tvedöra. Each group is labeled according to the corresponding $X$. tropicalis chromosome; units are given in Kosambi cM. (a) $L G_{2}$ and $L G_{7}$ (corresponding to Xt1 and Xt2) co-segregate in males from Ammarnäs, but not in Tvedöra (maps based on all 12 families). Dashed lines indicate absence of physical fusion and independent segregation in females. (b) All other linkage groups show similar patterns in the two populations (maps based on one family from Ammarnäs and six from Tvedöra). Dashed lines in group Xt 7A indicate that Bfg203 and Bfg238 are otherwise known to belong to the same linkage group, even though they were not significantly linked in the present study. 

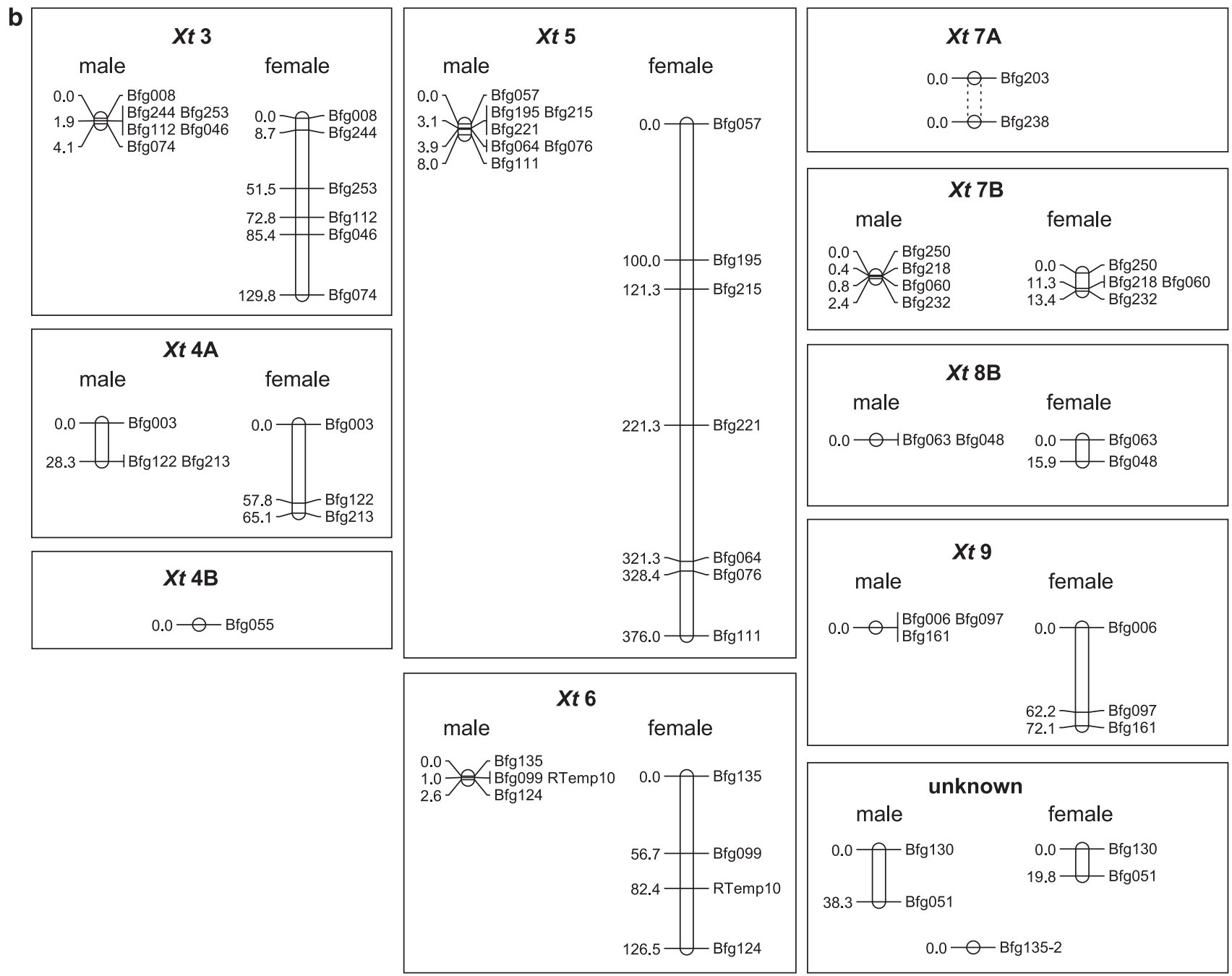

Figure 1 Continued

component of sex determination (Piquet, 1930; Rodrigues et al., 2015) that might be predominant or exclusive in the 'undifferentiated' race, but absent from the 'differentiated' race. Which epigenetic factors might contribute to sex determination, and why their importance seemingly correlates with climate, remain open questions.

In contrast, results from Ammarnäs provide evidence for strict sex linkage of $\mathrm{LG}_{7}$ in addition to $\mathrm{LG}_{2}$. Sibship analyses show these two genomic regions to co-segregate during male meiosis, with no recombination. Moreover, population-genetic analyses point to significant $\mathrm{LG}_{7}$ differentiation between sexes $\left(F_{\mathrm{ST}}=0.096\right)$ because of strong $\mathrm{X}-\mathrm{Y}$ divergence (male $F_{\mathrm{IS}}=-0.236$ ). PCAGEN plots illustrate this marked differentiation, both between sexes (Figure 3a) and between $\mathrm{X}$ and $\mathrm{Y}$ haplotypes (Figure 2). The only exception is male $\mathrm{A}_{17 \mathrm{M}}$, the $\mathrm{Y}$ haplotype of which is intermediate between $\mathrm{X}$ and $\mathrm{Y}$ clusters for both $L_{2}$ and $L_{7}$ markers, possibly suggesting a recent recombination event. PCAGEN plots moreover suggest absence of sex linkage for $\mathrm{LG}_{7}$ in all other populations investigated (Figures $3 \mathrm{~b}-\mathrm{f}$ ). This contrasts sharply with $\mathrm{LG}_{2}$, for which a few males from most populations show distinct $\mathrm{LG}_{2} \mathrm{Y}$ haplotypes (Rodrigues et al., 2014). The same seems to be true from all Swiss populations investigated so far: population-genetic studies have documented sex differentiation for
$\mathrm{LG}_{2}$ markers only, and sibship analyses have consistently shown independent segregation of $\mathrm{LG}_{7}$ and $\mathrm{LG}_{2}$, with only the latter involved in sex determination (Rodrigues et al., 2013). Thus, a parsimonious interpretation is that $L_{2}$ is the ancestral sex chromosome in $R$. temporaria, with the recent and seemingly localized addition of $\mathrm{LG}_{7}$. Postglacial colonization of northern-boreal regions by common frogs occurred very lately ( $<10 \mathrm{kya}$; Palo et al., 2004). Generation time under harsh climates can be estimated to 8 years (assuming age at first reproduction to be 4 years and annual survival rate $80 \%$; Miaud et al., 1999), possibly more because fecundity increases with age. Hence, given the short timeframe since postglacial colonization (in the order of 1000 generations) and its seemingly localized distribution, this neo-sex chromosome system might be the youngest one described so far.

It might seem surprising in this context that genetic differentiation between sexes and haplotypes appears as strong on $\mathrm{LG}_{7}$ as on $\mathrm{LG}_{2}$ in Ammarnäs, with similar $F_{\mathrm{ST}}$ values between $\mathrm{X}$ and $\mathrm{Y}$, and similarly depressed $\theta$ values on Y haplotypes. It should be reminded, however, that sex chromosomes do occasionally recombine in amphibians, regularly resetting XY similarity over evolutionary times (as indeed observed in Tvedöra). A plausible scenario would be that the last event of $\mathrm{X}-\mathrm{Y}$ recombination occurred relatively recently in the ancestry of 
Table 2 Fixation and diversity indices for $L G_{2}$ and $L G_{7}$ in adults of Ammarnäs and Tvedöra (2013 sampling, $n=40$ and 22 respectively)

\begin{tabular}{|c|c|c|c|c|}
\hline Ammarnäs & \multicolumn{2}{|c|}{ LG2 } & \multicolumn{2}{|c|}{ LG7 } \\
\hline$F_{\mathrm{ST}}$ & \multicolumn{2}{|c|}{0.108} & \multicolumn{2}{|c|}{0.096} \\
\hline \multirow[t]{2}{*}{$P$-value } & \multicolumn{2}{|c|}{0.010} & \multicolumn{2}{|c|}{0.010} \\
\hline & $M$ & $\mathrm{~F}$ & M & $\mathrm{F}$ \\
\hline$F_{\text {IS }}$ & -0.235 & 0.029 & -0.236 & 0.051 \\
\hline$H_{S}$ & 0.673 & 0.717 & 0.508 & 0.534 \\
\hline$X$ vs $Y$ & \multicolumn{2}{|c|}{ LG2 } & \multicolumn{2}{|c|}{ LG7 } \\
\hline$F_{\mathrm{ST}}$ & \multicolumn{2}{|c|}{0.415} & \multicolumn{2}{|c|}{0.441} \\
\hline \multirow[t]{2}{*}{$P$-value } & \multicolumn{2}{|c|}{0.007} & \multicolumn{2}{|c|}{0.003} \\
\hline & MY & MX & MY & MX \\
\hline$H_{S}$ & 0.286 & 0.687 & 0.201 & 0.511 \\
\hline Theta & 0.479 & 4.606 & 0.283 & 1.586 \\
\hline Tvedöra & \multicolumn{2}{|c|}{ LG2 } & \multicolumn{2}{|c|}{ LG7 } \\
\hline$F_{\mathrm{ST}}$ & \multicolumn{2}{|c|}{-0.001} & \multicolumn{2}{|c|}{-0.007} \\
\hline \multirow[t]{2}{*}{$P$-value } & \multicolumn{2}{|c|}{0.800} & \multicolumn{2}{|c|}{0.460} \\
\hline & M & $F$ & M & $F$ \\
\hline$F_{I S}$ & 0.066 & 0.072 & 0.008 & 0.068 \\
\hline$H_{\mathrm{S}}$ & 0.846 & 0.821 & 0.608 & 0.653 \\
\hline
\end{tabular}

For both linkage groups, the Ammarnäs population presents significant male $F_{\text {IS }}$ values, as well as significant $F_{S T}$ values both between sexes and between $X-Y$ haplotypes. M, F refer to males and females, while MY, MX refer to the phased $Y$ and $X$ haplotypes.
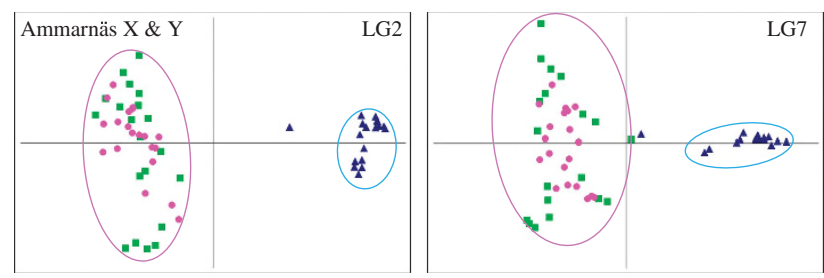

Figure 2 Principal component analysis (PCA) plots of $L G_{2}$ and $L G_{7}$ in Ammarnäs (2013 samples), with phased male haplotypes. For both linkage groups, the $\mathrm{Y}$ haplotypes (blue triangles) cluster apart from male $\mathrm{X}$ haplotypes (green squares), the latter clustering together with female genotypes (pink circles). The $Y$ outlier is male $A 17_{M}$. $L G_{2}$ plot updated from Rodrigues et al. (2015).

the Ammarnäs population, and simultaneously so for $\mathrm{LG}_{2}$ and $\mathrm{LG}_{7}$, followed by a rapid drop in gene diversity on the two Y chromosomes because of strong drift and Hill-Robertson interferences. It might actually be that the appearance of the neo-sex chromosome was instrumental in inducing the arrest of $\mathrm{X}-\mathrm{Y}$ recombination documented in this population (see below).

The mechanism underlying co-segregation does not appear to be a simple fusion: preliminary cytogenetic analyses of Ammarnäs froglets have revealed 13 pairs of chromosomes in both sexes (unpublished results). Absence of physical fusion is corroborated by our analysis of the female recombination map that suggests independent segregation of $\mathrm{LG}_{2}$ and $\mathrm{LG}_{7}$ in this sex. Co-segregation in males might instead result from a reciprocal translocation between the original $\mathrm{Y}\left(\mathrm{LG}_{2}\right)$ and an autosome $\left(\mathrm{LG}_{7}\right)$. Such a translocation is expected to generate a tetravalent during male meiosis, a scenario that might be tested by karyotypic analysis of male testes. Neo-sex chromosomes resulting from reciprocal translocations have been documented in both animals and plants (see, for example, Howell et al., 2009), with patterns of translocation that may also vary between populations (see, for example, Grabowska-Joachimiak et al., 2015). Co-segregation of multiple sex chromosomes has notably been documented in some populations of Rana tagoi, where male heteromorphy for C-banding
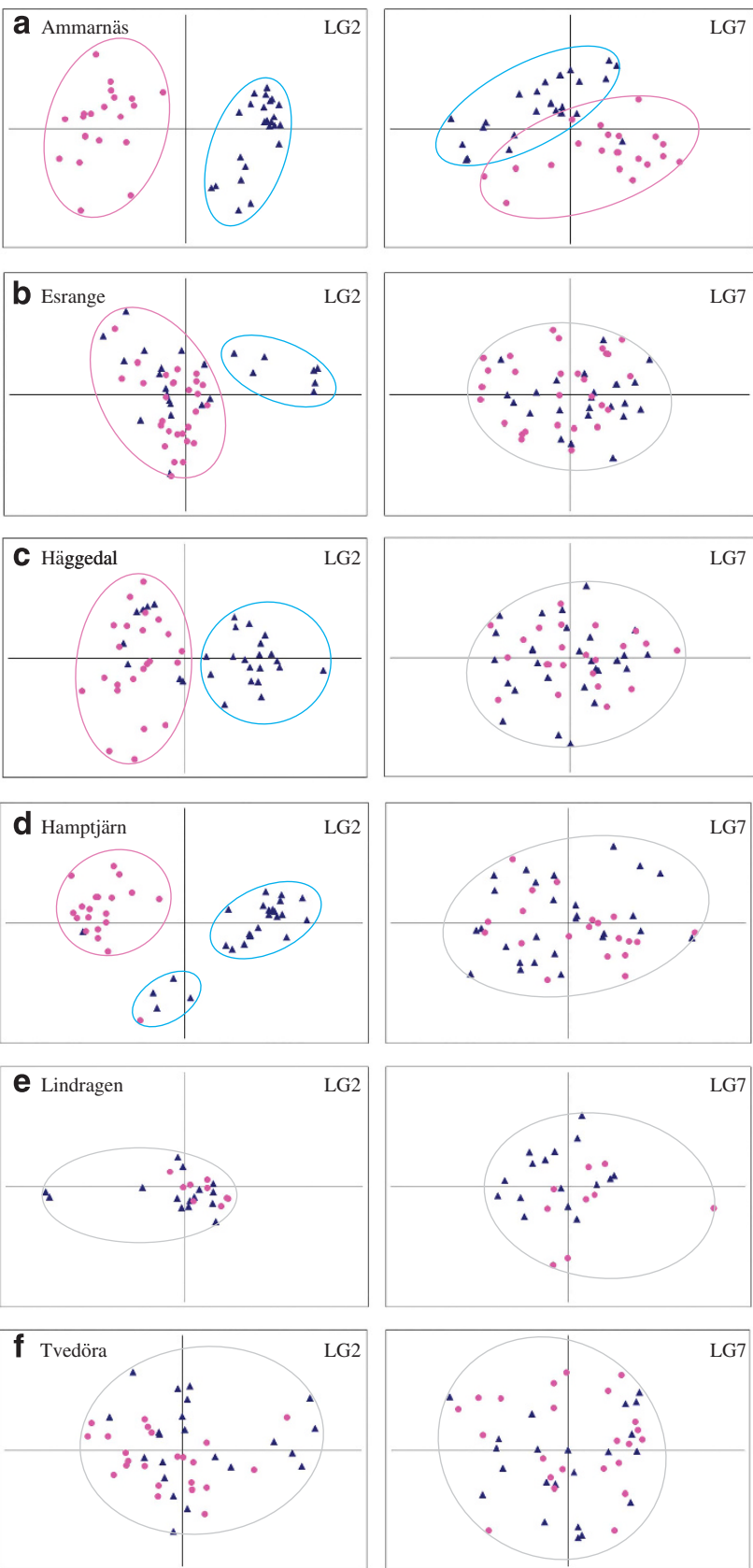

Figure 3 Principal component analysis (PCA) plots of $L_{2}$ and $L_{7}$ in six Swedish populations (1998-1999 samples). For $\mathrm{LG}_{7}$, males (blue triangles) and females (pink circles) form differentiated clusters in Ammarnäs (a) but not in any of all other populations (b-f). $\mathrm{LG}_{2}$ plots updated from Rodrigues et al. (2014).

patterns suggests that both chromosome pairs 8 and 9 co-segregate as sex chromosomes (Ryuzaki et al., 1999). In some cases multiple translocations are involved, resulting in a multivalent chain of chromosomes during male meiosis (see, for example, Barlow and Wiens, 1976; Syren and Luykx, 1977; Grützner et al., 2004; Gazoni et al., 2012).

The fixation of a neo-sex chromosome can result from genetic drift alone, but selective forces might also be involved. As pointed out by Charlesworth and Charlesworth (1980), translocations or centric fusions between a sex chromosome and an autosome might create favorable linkage between sex-determining genes and sexually 
antagonistic genes. This selective force has been invoked to account for the fixation of a centric fusion in a Japanese species of sticklebacks, by which the ancestral sex chromosomes get linked with autosomal loci involved in male courtship display (Kitano et al., 2009). R. temporaria $\mathrm{LG}_{2}$ maps to Xt chromosome 1 (Brelsford et al., 2013, 2016) that contains the candidate sex-determining genes Dmrtl and Amh. The former is thought to determine sex in birds (Smith et al., 2009), whereas paralogs play this role in species of fish and frogs (Matsuda et al., 2002; Nanda et al., 2002; Yoshimoto et al., 2010). The antiMullerian hormone Amh likely determines sex in platypus (Cortez et al., 2014), whereas a paralog has been shown to play this role in a fish (Hattori et al., 2012). LG 7 maps to Xt chromosome 2 (Figure 1) that carries the gene Amhr2 encoding the receptor for Amh, also known to determine sex in some fish (Kamiya et al., 2012). A strict linkage between these important genes involved in the sexdetermination cascade might contribute to the 'differentiated race' syndrome documented in Ammarnäs, namely strict genetic sex determination and early gonadal differentiation during embryonic development. By the same token, the strongly masculinizing effects of this neo-sex chromosome might have been instrumental in preventing sex reversal and thereby definitively stopping $\mathrm{X}-\mathrm{Y}$ recombination in this population (Perrin, 2009), hence accounting for the similar levels of $\mathrm{X}-\mathrm{Y}$ differentiation between $\mathrm{LG}_{2}$ and $\mathrm{LG}_{7}$ markers.

It would be worth extending the present analyses to a broader geographical scale. In particular, there is a need to investigate more populations from the 'differentiated race' (including high-altitude populations from the Alps) to see whether $\mathrm{LG}_{7}$ is also involved locally, or whether analogous processes occurred independently to foster the 'differentiated race' syndrome. The striking intraspecific polymorphism documented here also offers a remarkable potential to investigate the evolution of sexually antagonistic and sex-determining genes on different chromosomes ( $\mathrm{LG}_{2}$ and $\mathrm{LG}_{7}$ ) that present variable association to sex. Altogether, $R$. temporaria seemingly provides an ideal system to study the neutral and selective forces acting on the evolution of sex-determination mechanisms.

\section{DATA ARCHIVING}

Raw genotypes of 12 families for 62 microsatellite loci are available from the Dryad Digital Repository at doi:10.5061/dryad.253h0.

\section{CONFLICT OF INTEREST}

The authors declare no conflict of interest.

\section{ACKNOWLEDGEMENTS}

We thank Jon Loman for help in the field sampling, Marika Hölttä for help in obtaining permissions, Roberto Sermier for help in wetlab analyses, Kim Schalcher for help with genotyping and statistical analyses and the Swiss National Science Foundation for funding (grant 31003B_147091 to NP). Capture permits were delivered by the prefectures of Skåne and Västerbotten counties for Tvedöra (522-363-2013) and Ammarnäs (522-3396-2013). An additional permit was delivered for Ammarnäs as part of the nature reserve of Vindelfällen (521-3407-2013). Ethical permits were delivered by the Swedish Board of Agriculture for Tvedöra (M 19-13) and Ammarnäs (A 10-13), and by the Veterinary Office of the Canton Vaud, Switzerland (authorization 2287).

Alho JS, Matsuba C, Merilä J (2010). Sex reversal and primary sex ratios in the common frog (Rana temporaria). Mol Ecol 19: 1763-1773.

Barlow BA, Wiens D (1976). Translocation heterozygosity and sex ratio in Viscum fischeri. Heredity 37: 27-40.
Brelsford A, Rodrigues N, Perrin N (2016). High-density linkage maps fail to detect any genetic component to sex determination in a Rana temporaria family. J Evol Biol 29: 220-225.

Brelsford A, Stöck M, Betto-Colliard C, Dubey S, Dufresnes C, Jourdan-Pineau H et al. (2013). Homologous sex chromosomes in three deeply divergent anuran species. Evolution 67: 2434-2440.

Broquet T, Berset-Brändli L, Emaresi G, Fumagalli L (2007). Buccal swab allow efficient and reliable microsatellite genotyping in amphibians. Conserv Genet 8: 509-511.

Cano JM, Li MH, Laurila A, Vilkki J, Merilä J (2011). First-generation linkage map for the common frog Rana temporaria reveals a sex linkage group. Heredity 107: 530-536.

Charlesworth D, Charlesworth B (1980). Sex differences in fitness and selection for centric fusions between sex chromosomes and autosomes. Genet Res 35: 205-214.

Cortez D, Marin R, Toledo-Flores D, Froidevaux L, Liechti A, Waters PD et al. (2014). Origins and functional evolution of $Y$ chromosomes across mammals. Nature 508: 488-493.

Dufresnes C, Borzée A, Horn A, Stöck M, Ostini M, Sermier R et al. (2015). Sex-chromosome homomorphy in Palearctic tree frogs results from both turnovers and X-Y recombination. Mol Biol Evol 32: 2328-2337.

Eggert C (2004). Sex determination: the amphibian models. Reprod Nutr Dev 44: 539-549.

Gazoni T, Gruber SL, Silva APZ, Araujo OGS, Narimatsu H, Strüssman C et al. (2012). Cytogenetic analyses of eight species in the genus Leptodactylus Fitzinger, 1843 (Amphibia, Anura, Leptodactylidae), including a new diploid number and a karyotype with multiple translocations. BMC Genet 13: 109.

Green P, Falls K, Crook S (1990). Documentation for CRIMAP, version 2.4. Washington University School of Medicine: St Louis, MO, USA.

Gosner KL (1960). A simplified table for staging anuran embryos and larvae with notes on identification. Herpetologica 16: 183-190.

Goudet J (1995). FSTAT (version 1.2): a computer program to calculate F-statistics. J Hered 86: 485-486.

Goudet J (1999). PCAGEN, a Program to Perform a Principal Component Analysis (PCA) on Genetic Data (Version 1.2). Population Genetics Laboratory, University of Lausanne: Lausanne, Switzerland.

Grabowska-Joachimiak A, Kula A, Książczyk T, Chojnicka J, Sliwinska E, Joachimiak AJ (2015). Chromosome landmarks and autosome-sex chromosome translocations in Rumex hastatulus, a plant with XX/XY1Y2 sex chromosome system. Chromosome Res 23: 187-197.

Grossen C, Neuenschwander S, Perrin N (2011). Temperature-dependent turnovers in sex-determination mechanisms: a quantitative model. Evolution 65: 64-78.

Grützner F, Rens W, Tsend-Ayush E, El-Mogharbel N, O'Brien PC, Jones RC et al. (2004). In the platypus a meiotic chain of ten sex chromosomes shares genes with the bird $Z$ and mammal X chromosomes. Nature 432: 913-917.

Haczkiewicz K, Ogielska M (2013). Gonadal differentiation in frogs: how testes become shorter than ovaries. Zool Sci 30: 125-134.

Hattori RS, Murai Y, Oura M, Masuda S, Majhi SK, Sakamoto T et al. (2012). A Y-linked anti-Müllerian hormone duplication takes over a critical role in sex determination. Proc Natl Acad Sci USA 109: 2955-2959.

Hettyey A, Laurila A, Herczeg G, Jönsson KI, Kovacs T, Merilä J (2005). Does testis weight decline towards the Subarctic? A case study on the common frog, Rana temporaria. Naturwissenschaften 92: 188-192.

Hjernquist MB, Söderman F, Jönsson KI, Herczeg G, Laurila A, Merilä J (2012). Seasonality determines patterns of growth and age structure over a geographic gradient in an ectothermic vertebrate. Oecologia 170: 641-649.

Howell EC, Armstrong SJ, Filatov DA (2009). Evolution of neo-sex chromosomes in Silene diclinis. Genetics 182: 1109-1115.

Ivanova NV, Dewaard JR, Hebert PDN (2006). An inexpensive automation-friendly protocol for recovering high-quality DNA. Mol Ecol Notes 6: 998-1002.

Kamiya T, Wataru K, Satoshi T, Ayumi O, Takayoshi M, Naoki M et al. (2012). A transspecies missense SNP in Amhr2 is associated with sex determination in the Tiger pufferfish, Takifugu rubripes (Fugu). PLoS Genet 8: e1002798.

Kimura M, Ohta T (1975). Distribution of allelic frequencies in a finite population under stepwise production of neutral alleles. Proc Natl Acad Sci USA 72: 2761-2764.

Kitano J, Ross JS, Mori S, Kume M, Jones FC, Chan YF et al. (2009). A role for a neo-sex chromosome in stickleback speciation. Nature 461: 1079-1083.

Matsuba C, Miura I, Merilä J (2008). Disentangling genetic vs. environmental causes of sex determination in the common frog, Rana temporaria. BMC Genet 9: 3.

Matsuda M, Nagahama Y, Shinomiya A, Sato T, Matsuda C, Kobayashi T et al. (2002). DMY is a Y-specific DM-domain gene required for male development in the medaka fish. Nature 417: 559-563.

Miaud C, Guyétant R, Elmberg J (1999). Variations in life-history traits in the common frog Rana temporaria (Amphibia: Anura): a literature review and new data from the French Alps. J Zool London 249: 61-73.

Miura I (2007). An evolutionary witness: the frog Rana rugosa underwent change of heterogametic sex from XY male to ZW female. Sex Dev 1: 323-331.

Nanda I, Kondo M, Hornung U, Asawaka S, Winkler C, Shimizu A et al. (2002). A duplicated copy of DMRT1 in the sex-determining region of the $Y$ chromosome of the medaka, Oryzias latipes. Proc Natl Acad Sci USA 99: 11778-11783.

Nishioka M, Sumida M (1994). The position of sex-determining genes in the chromosomes of Rana nigromaculata and Rana brevipoda. Sci Rep Lab Amph Biol Hiroshima Univ 13: 51-97.

Ogielska M, Kotusz A (2004). Pattern and rate of ovary differentiation with reference to somatic development in anuran amphibians. J Morphol 259: 41-54.

Palo JU, Schmeller DS, Laurila A, Prier CR, Kuzmin SL, Merilä J (2004). High degree of population subdivision in a widespread amphibian. Mol Ecol 13: 2631-2644. 
Perrin N (2009). Sex reversal: a fountain of youth for sex chromosomes? Evolution 63: 3043-3049.

Piquet J (1930). Détermination du sexe chez les Batraciens en fonction de température. Rev Suisse Zool 37: 173-281.

Rodrigues N, Betto-Colliard C, Jourdan-Pineau H, Perrin N (2013). Within-population polymorphism of sex-determination systems in the common frog (Rana temporaria). J Evol Biol 26: 1569-1577.

Rodrigues N, Merilä J, Patrelle C, Perrin N (2014). Geographic variation in sex-chromosome differentiation in the common frog (Rana temporaria). Mol Ecol 23: 3409-3418.

Rodrigues N, Vuille Y, Loman J, Perrin N (2015). Sex-chromosome differentiation and 'sex races' in the common frog (Rana temporaria). Proc $R$ Soc B 282: 20142726.

Ryuzaki M, Hanada H, Okumoto H, Takizawa N, Nishioka M (1999). Evidence for heteromorphic sex chromosomes in males of Rana tagoi and Rana sakuraii in Nishitama district of Tokyo (Anura: Ranidae). Chromosome Res 7: 31-42.

Smith CA, Roeszler KN, Ohnesorg T, Cummins DM, Farlie PG, Doran TJ et al. (2009). The avian Z-linked gene Dmrt1 is required for male sex determination in the chicken. Nature 461: 276-271.
Stöck M, Horn A, Grossen C, Lindtke D, Sermier R, Betto-Colliard C et al. (2011). Ever-young sex chromosomes in European tree frogs. PLoS Biol 9: e1001062.

Syren RM, Luykx P (1977). Permanent segmental interchange complex in the termite Incisitermes schwarzi. Nature 266: 167-168.

Voorrips RE (2002). MapChart: software for graphical presentation of linkage maps and QTLs. J Hered 93: 77-78.

Witschi E (1929). Studies on sex differentiation and sex determination in amphibians. III. Rudimentary hermaphroditism and Y chromosome in Rana temporaria. J Exp Zool 54: 157-223.

Witschi E (1930). Studies on sex differentiation and sex determination in amphibians. IV. The geographical distribution of the sex races of the European grass frog (Rana temporaria, L.). J Exp Zool 56: 149-165.

Yoshimoto S, Ikeda N, Izutsu Y, Shiba T, Takamatsu N, Ito M (2010). Opposite roles of DMRT1 and its W-linked paralogue, DM-W, in sexual dimorphism of Xenopus laevis: implications of a ZZ/ZW-type sex-determining system. Development 137: 2519-2526.

Supplementary Information accompanies this paper on Heredity website (http://www.nature.com/hdy) 